\title{
Peningkatan Kualitas Batubara Subbituminus Mallawa Menjadi Batubara Bituminus
}

\author{
Swastanti Brotowati ${ }^{1, a)}$, dan Irwan Sofia ${ }^{2, b)}$ \\ ${ }^{1}$ Jurusan Teknik Kimia, PNUP, Jl. Perintis Kemerdekaan Km 10 Tamalanrea Makassar \\ ${ }^{2}$ Jurusan Teknik Kimia, PNUP, Jl. Perintis Kemerdekaan Km 10 Tamalanrea Makassar \\ ${ }^{a}$ swastantib@poliupg.ac.id

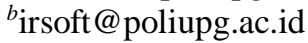

\begin{abstract}
Abstract Coal from Mallawa Bone regency of South Sulawesi includes low rank coal or subbituminus rank type $C$. The results of chemical analysis showed that content of water $2.64 \%$, fly ash $46.16 \%$, ash $15.26 \%$, fixec carbon $35.96 \%$, sulfur $1,73 \%$ and heat value $5190 \mathrm{kcal} / \mathrm{kgram}$. The desulfurization process using HCL solution $20 \%$ and demineralization process using $20 \% \mathrm{NaOH}$ solution followed by carbonization or combustion process at $400{ }^{\circ} \mathrm{C}$ in the furnace with little air. Result of the reseach with water content of $1.66 \%$, fly content $13,35 \%$, ash content $6,78 \%$, carbon content bound $78,21 \%$, sulfur content $0,43 \%$ and calorific value 7097.24 kcal / kgram. Based on ASTM D338 and SNI 13-6011-1999 coal of the research results included in type low volatile bittuminus type $C$.
\end{abstract}

Keywords: Subbittuminus, Bittuminus, desulfurization, demineralization, carbonization

\begin{abstract}
Abstrak-Abstrak Batubara asal desa Mallawa , Kabupaten Bone Sulawesi Selatan termasuk batubara peringkat rendah jenis subbituminus type $\mathrm{C}$ Hasil analisis kimia menunjukkan kadar air $2.64 \%$, kadar zat terbang $46.16 \%$, kadar abu $\mathbf{1 5 . 2 6 \%}$, kadar karbon terikat $35.96 \%$, kadar sulfur $\mathbf{2 . 1 9 \%}$ dan nilai kalor 5190 kkal/kgram. Dengan proses desulfurisasi menggunakan larutan $\mathrm{HCl} \mathbf{2 0 \%}$ dan demineralisasi menggunakan larutan $\mathrm{NaOH} 20 \%$, dilanjutkan dengan proses karbonisasi atau pembakaran pada suhu $400^{\circ} \mathrm{C}$ dalam tungku pembakaran dengan sedikit udara . Hasilnya kadar air $1,66 \%$, kadar zat terbang $13,35 \%$, kadar abu $6,78 \%$, kadar karbon terikat $\mathbf{7 8 , 2 1 \%}$, kadar sulfur $0,43 \%$ dan nilai kalor 7097,24 kkal/kgram. Berdasarkan ASTM D338 dan SNI 13-6011-1999 batubara hasil penelitian termasuk dalam type atau rank low volatile bittuminus type $C$
\end{abstract}

Kata Kunci: Subbittuminus, Bittuminus, desulfurisasi, demineralisasi, karbonisasi

\section{Pendahuluan}

Indonesia memiliki cadangan batubara yang besar melebihi cadangan minyak bumi. Komoditi Batubara ini harapkan mampu menjadi sumber alternatif pengganti minyak bumi, selain untuk ekspor juga untuk memenuhi kebutuhan konsumsi energi dalam negeri. Mengingat Indonesia memiliki deposit sumber daya batubara sebesar 161 miliar ton, tetapi $79,94 \%$ adalah batubara kualitas rendah, sedangkan batubara dengan kualitas baik hanya sekitar 21,06\% dari total deposit yang terbanyak sekitar $79,94 \%$ dari total cadangan sebesar 161 miliar ton $[1,11]$.

Sulawesi Selatan memiliki cadangan batubara sebanyak 38,3 juta ton, yang tersebar di Kabupaten Maros, Barru, Pangkep, Sidrap, Enrekang, Sidrap, Sinjai dan Bone. Daerah Malawa di Kabupaten Bone memiliki cadangan batubara terbesar sekitar 18,3 juta ton, batubara dengan kualitas rendah mempunyai kadar air 2.64\%, kadar zat menguap/ zat terbang $46.16 \%$, kadar abu $15.26 \%$, kadar karbon terikat (fixed carbon) $35.96 \%$, kadar sulfur $1.73 \%$ dan nilai kalor $5190 \mathrm{kkal} / \mathrm{kgram}$, Berdasarkan klasifikasi ASTM D 336 batubara asal Mallawa termasuk dalam katagori, i batubara jenis subbituminus type C.Batubara jenis ini jika dijual memilki harga sangat murah, karena nilai kalor rendah, kandungan sulfur diatas $1 \%$, kadar karbon tetapnya rendah ,sehingga jika dibakar akan mengotori lingkungan $[1,3,4]$.

Batubara ini akan di proses untuk menaikkan rank/tingkatan kualitasnya dari rank subbituminus menjadi rank bituminous melalui proses desulfurisasi, demineralisasi dan dilanjutkan dengan proses karbonisasi. Proses desulfurisasi menggunakan larutan $\mathrm{HCl} 20 \%$ bertujuan untuk mengurangi kandungan sulfur dalam batubara, kemudian tahapan dilanjutkan dengan proses demineralisasi menggunakan larutan $\mathrm{NaOH} 20 \%$ untuk menurunkan kandungan abu batubara dan selanjutnya dibakar dalam tungku dengan sedikit atau tanpa udara pada suhu yang divariasikan. Tujuan dari proses pembakaran atau karbonisasi untuk menurunkan kandungan zat terbang/volatile matter dan 
menaikkan kadar karbon tetap. Sedangkan pada tahap proses desulfurisasi dan demineralisasi dilakukan pada kondisi operasi : tekanan 1 atm, suhu $90^{\circ} \mathrm{C}$, kecepatan pengadukan $250 \mathrm{rpm}$, dengan waktu reaksi yang divariasikan,

dengan harapan batubara asal desa Mallawa ini dapat ditingkatkan kualitasnya sehingga nilai jualnya akan meningkat [3].

Menurut klasifikasi tingkatan / rank batubara sesuai ASTM- D338, dan SNI 13-6011-1999

Batubara yang termasuk dalam Low - Volatile Bituminous ; merupakan group batubara dalam rank bituminous yang mengandung persentase fixed carbon sebesar $>78 \%-<86 \%$ serta persentase kandungan volatile matternya sebesar $>14 \%$ $<22 \%$,sedang Medium-Volatile Bituminous; merupakan grup batubara dalam rank bituminous yang memiliki kandungan fixed carbon sebesar $>69 \%$ - $<78 \%$ kandungan volatile matter sebesar >22\%$<31 \%$. High-Volatile A Bituminous; adalah grup batubara dalam rank bituminous yang memiliki persentase fixed carbon sebesar $<69 \%$, persentase kandungan volatile matternya sebesar $>31 \%$, serta nilai kalorinya $>14000 \mathrm{BTU} / \mathrm{lb}$.

High - Volatile B Bituminous merupakan batubara dalam rank bituminous yang mempunyai nilai kalori sebesar $>13000$ BTU/lb-<14000 BTU/lb, sedang High-Volatile C Bituminous; merupakan batubara dalam rank bituminous yang mempunyai nilai kalori sebesar $>11500 \mathrm{BTU} / \mathrm{lb}-<13000 \mathrm{BTU} / \mathrm{lb}$ $[1,2]$

\section{Metode Penelitian}

Bahan baku : Batubara asal Mallawa Bone Sulawesi Selatan, hasil analisis batubara mempunyai kadar air $2.64 \%$, kadar zat menguap/ zat terbang $46.16 \%$, kadar abu $15.26 \%$, kadar karbon terikat (fixed carbon) $35.96 \%$, kadar sulfur $1.73 \%$ dan nilai kalor $5190 \mathrm{kkal} / \mathrm{kgram}$.

Kondisi operasi : proses desulfurisasi dan demineralisasi ditetapkan sebagai berikut: kecepatan pengadukan $250 \mathrm{rpm}$, temperatur: $90^{\circ} \mathrm{C}$, tekanan operasi : $1 \mathrm{~atm}$,waktu reaksi divariasikan 60,120, 180, 240 dan 300 menit, konsentrasi larutan $\mathrm{HCl} 20 \%$ dan $\mathrm{NaOH} 20 \%[3,5,11]$. Proses pembakaran atau karbonisasi divariasikan : 60, 120,180 dan 240 menit , suhu karbonisasi dimualai dari :300, $400,500^{\circ} \mathrm{C}$.

Metode analisis: analisis proksimat dan ultimat meliputi meliputi : volatil metter /zat terbang dengan metode British Standard (BS. 1016), kadar air menggunakan metode ASTM designation D.3173-92, kadar abu menggunakan metode ASTM designation D. 3174-98., kadar Sulfur menggunakan metode Eschka dan Brukker XRay, kadar fixed carbon dihitung berdasarkan persamaan:Fixed Carbon $=100 \%$-(kadar air+kadar zat terbang+kadar abu ) [2].

\section{Proses Desulfurisasi dan demineralisasi}

Pada langkah awal sebelum reaksi dijalankan, bak minyak silikon dipanaskan terlebih dahulu menggunakan sistem pemanas yang telah di set pada suhu reaksi yang diinginkan. Reaktor dalam bak minyak silicon diisi dengan larutan $\mathrm{NaOH} 20 \%$ kemudian dicampurkan dengan batubara pada ratio 5:1 suhu di set $90{ }^{\circ} \mathrm{C}$ dan tekanan $1 \mathrm{~atm}$, kecepatan pengadukan 250rpm dan waktu reaksi selama divariasikan

Reaksi dihentikan setelah waktu reaksi tercapai dan mencelupkan reaktor ke dalam bak air dingin. Selanjutnya dilakukan pencucian dan penyaringan dengan air hingga $\mathrm{pH}$ netral yaitu $\mathrm{pH} 7$ dan dikeringkan dengan diangin angin selama 24 jam dipastikan batubara sedah kering.

Langkah berikutnya batubara hasil desulfurisasi dilanjutkan dengan proses demineralisasi dengan perlakukan dan kondisi operasi yang sama

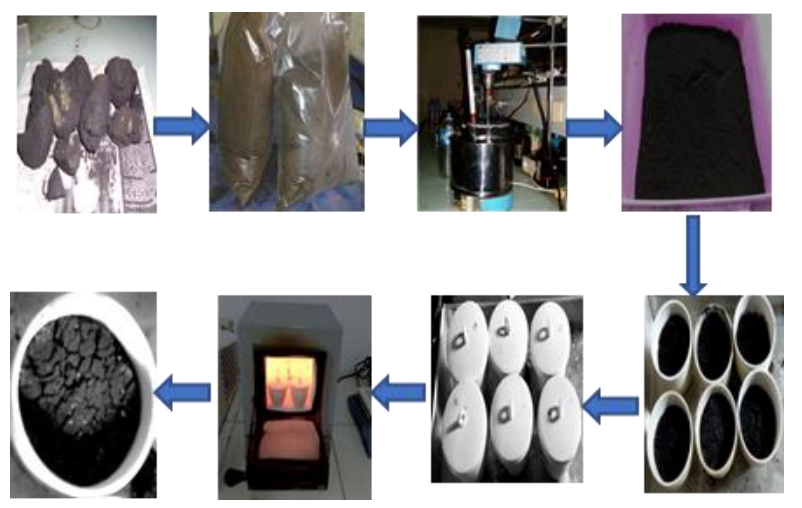

Gambar 1.Rangkaian alat percobaan

Siklus rangkaian percobaan dapat dilihat pada gambar 1., terdiri atas proses desulfurisasi, demineralisasi dan proses karbonisasi atau pembakaran batubara hasil desulfurisasi dan demineralisasi, selanjutnya dilakukan analisis proksimat dan ultimat meliputi kadar air, kadar sulfur, kadar abu, kadar zat tembang / VM dan karbon terikat 


\section{Hasil dan Pembahasan}

\section{A. Proses Desulfurisasi dan Demineralisasi}

Proses desulfurisas adalah proses pengurangan kandungan sulfur batubara, dan proses demineralisai adalah proses pengurangan kandungan abu batubara. Proses desulfurisasi dilakukan dengan menggunakan larutan $\mathrm{HCl} 20 \%$ dan proses demineralisasi dilakukan dengan menggunakan larutan $\mathrm{NaOH} 20 \%$ Kedua proses dilakukan pada kondisi operasi suhu $90^{\circ} \mathrm{C}$, tekanan 1 atm, kecepatan pengadukan $250 \mathrm{Rpm}$, sedangkan waktu reaksi divariasikan $[3,5,11]$.

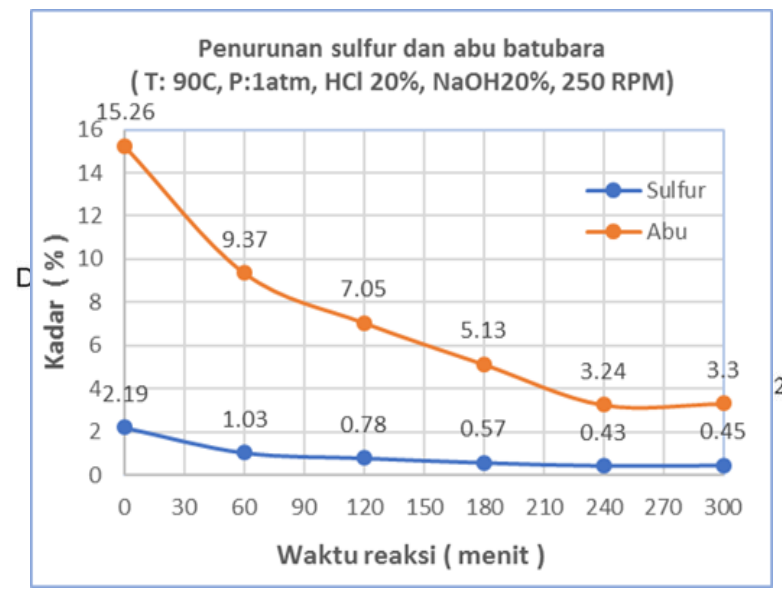

Gambar 2. Hasil penurunan sulfur dan abu batubara

Pada gambar 2 menujukkan bahwa sulfur dalam batubara terikat sebagai $\mathrm{FeS}_{2}$, larutan $\mathrm{HCL} 20 \%$ memiliki sejumlah atom $\mathrm{Cl}^{-}$yang cukup untuk berikatan dengan $\mathrm{Fe}^{2+}$ dan atom $\mathrm{H}^{+}$dengan $\mathrm{S}^{2-}$ yang cukup reaktif membentuk senyawa baru $\mathrm{FeCl}_{2}$ dan gas $\mathrm{H}_{2} \mathrm{~S}$ dengan bertambahnya waktu maka ikatan semakin reaktif/kuat mengikat senyawa di sekitarnya dan akan berkurang keaktifannya pada waktu tertentu. Seperti nampak pada gambar 1, di atas 240 menit keaktifan masing-masing atom mulai berkurang.

Abu dalam batubara merupakan senyawa $\mathrm{Si}, \mathrm{Al}$, $\mathrm{Fe}, \mathrm{Cr}$ dan sedikit $\mathrm{Ti}, \mathrm{Mn}, \mathrm{Mg}, \mathrm{Na}$ dan $\mathrm{K}$ Larutan alkali $\mathrm{NaOH} 20 \%$ mempunyai kemampuan cukup kuat untuk melarutkan senyawa mineral dalam abu batubara. Bertambahnya waktu maka keaktifan dari proses pelarutan akan semakin besar dan akan berkurang keaktifannta pada waktu tertentu $[3,4,11]$

Konversi berhubungan erat dengan waktu reaksi , semakin besar waktu reaksi semakin banyak hasil yang diperoleh, dan pada waktu tertentu akan terjadi kesetimbangan reaksi, yang berarti tidak ada lagi hasil reaksi yang akan diperoleh. Hal ini dapat dilihat pada gambar 2, konversi maksimum yang diperoleh pada waktu reaksi 240 menit

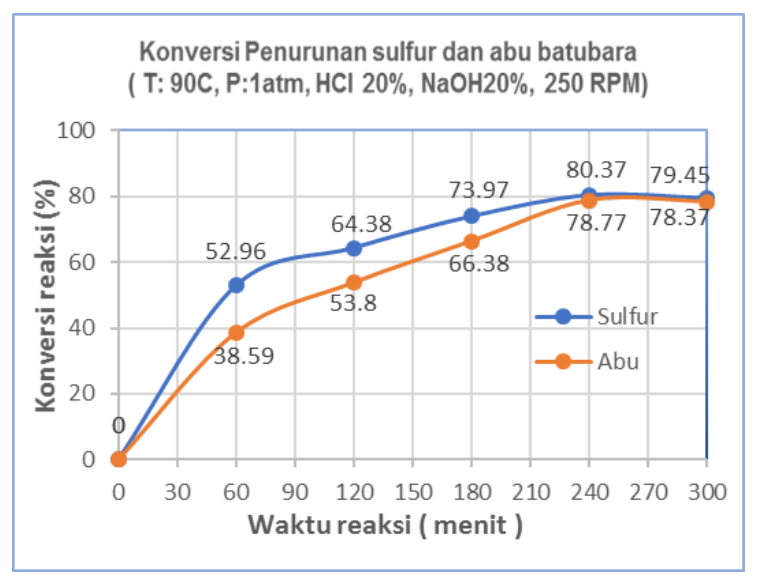

Gambar 3. Konversi reaksi penurunan sulfur dan abu batubara

\section{B. Proses pembakaran batubara atau proses karbonisasi}

\section{Pengaruh proses pembakaran terhadap Volatile Matter}

Proses karbonisasi terjadi berlangsung secara endoterm atau eksoterm tergantung pada temperatur dan proses reaksi yang sedang terjadi. Secara umum proses karbonisasi dipengaruhi oleh temperatur, waktu proses, sifat reaksi, dan perubahan fisik/kimiawi yang terjadi. Tahap karbonisasi, adalah bahan baku dipanaskan tanpa udara dan tanpa penambahan zat kimia. Dengan tujuan untuk menghilangkan zat terbang dan gas-gas lain yang ada dalam batubara atau biasa disebut dengan istilah zat volatile matter

Kadar zat terbang atau volatile matter merupakan hasil dekomposisi zat-zat penyusun arang akibat proses pemanasan selama pengarangan dan bukan komponen penyusun arang. Kadar zat terbang akan menurun seiring dengan meningkatnya suhu karbonisasi dan waktu karbonisasi, karena ketidak sempurnaan penguraian senyawa non karbon selama proses karbonisasi. Kadar zat terbang ditentukan oleh waktu dan suhu pengarangan $[6,7$, $8,9,10]$

Pada gambar 3 dapat dilihat suhu maksimum pembakaran untuk menghasilkan Volatile matter yang telah memenuhi syarat sebagai batubara bittuminus adalah pada suhu pembakaran $400^{\circ} \mathrm{C}$ dengan waktu pembakaran selama 240 menit. 


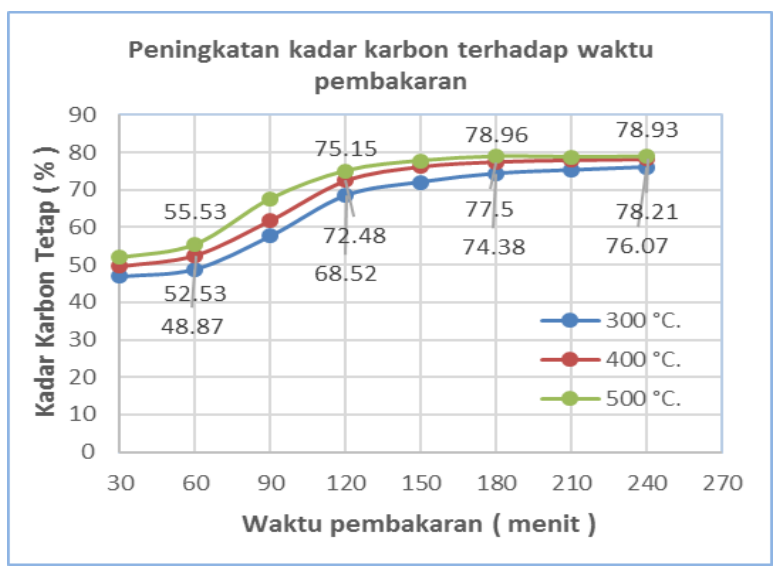

Gambar 4. Penurunan volatile matter terhadap peningkatan suhu pembakaran

\section{Pengaruh proses pembakaran terhadap Kadar karbon Tetap}

Kadar karbon merupakan jumlah karbon murni yang terkandung di dalam arang, semakin tinggi suhu pada proses karbonisasi/pembakaran akan berpengaruh pada kualitas dari arang, termasuk kadar karbon tetap atau karbon terikat. Kenaikan kadar karbon seiring dengan bertambahnya suhu karbonisasi mulai suhu karbonisasi 300,400 hingga $500^{\circ} \mathrm{C}$ terjadi kenaikkan kadar karbon. Waktu karbonisasi atau pembakaran di mulai di atas 90 menit hingga 240 menit penurunan kadar karbon, hal ini dikarenakan pada suhu yang terlalu tinggi, proses karbonisasi cenderung merusak dinding-dinding pori karbon sehingga karbon yang terbentuk semakin sedikit $[9,10,11]$ Sehingga kondisi optimum adalah pada suhu $400^{\circ} \mathrm{C}$ dan waktu 240 menit.

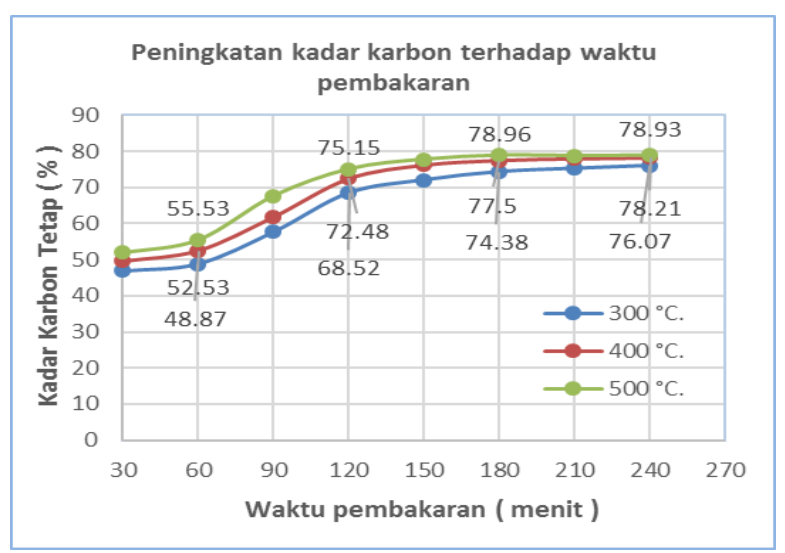

Gambar 5 Peningkatan Fixed karbon terhadap peningkatan suhu pembakaran
Perhitungan kadar Fixed Carbon tidak dapat dianalisis secara langsung, tetapi diperoleh dari hasil perhitungan sebagai berikut yaitu

$100 \%$ - (\% Ash -\% Moisture -\% Volatile Matter )

Fixed Carbon merupakan komponen utama dalam pembentukan batubara dan menentukan besar kecilnya nilai kalor akibat terjadinya pemutusan ikatan - ikatan karbon.dalam batubara akibat adanya penambahan suhu pembakaran..Dari gambar 4. dapat dilihat bahwa kadar fixed karbon meningkat seiring dengan peningkatan suhu dan waktu pembakaran. Kondisi optmal pembakaran dipilih pada suhu $400^{\circ} \mathrm{C}$ selama kurun waktu 240 menit.

Pada suhu $400^{\circ} \mathrm{C}$ dan waktu pembakaran 240 menit.ditetapkan sebagai kondisi optimal, Dimana sampel pada kondisi ini dilakukan analisis ultimat dan proksimat meliputi : kadar sulfur 0,43\%, abu 6,78\%, kadar air 1,66\%, volatile matter $13,35 \%$, karbon tetap Ifixed carbon $78,21 \%$.Abu dari batubara mengalami pertambahan pada saat proses pembakaran/karbonisasi terjadi kenaikan dari 3,24\% menjadi $6,78 \%$, hal ini disebabkan masih ada sedikit udara dalam tungku menyebabkan adanya karbon yang terbakar menjadi abu $[6,9]$.

\section{Kesimpulan}

Kesimpulan dari hasil penelitian dapat dijelaskan sebagai berikut :

1. Proses desulfurisasi dengan larutan $\mathrm{HCl} 20 \%$ dapat menurunkan kandungan sulfur dari 2,19\% menjadi $0,43 \%$, dari batubara asal Mallawa dengan konversi reaksi sebesar 80,37\%

2. Proses demineralisasi dengan larutan $\mathrm{NaOH}$ $20 \%$ dapat menurunkan kandungan abu dari $15,26 \%$ menjadi $3,24 \%$, dengan konversi reaksi sebesar $78,77 \%$

3. Proses pembakaran / karbonisasi batubara hasil desulfurisasi dan demineralisasi pada suhu $400^{\circ} \mathrm{C}$, selama 240 menit dapat ::

a. Meningkatkan kadar abu dari 2,19\% menjadi $6,78 \%$,hal ini terlihat masih adanya sedikit udara dalam tungku sehingga pada suhu tinggi akamn membakar karbon

b. Meningkatkan kadar karbon tetap / Fixe karbon dari 35,96\% menjadi 78,21\%

c. Menurunkan kadar Zat terbang/volatile matter dari $46,16 \%$ menjadi $13,35 \%$

d. Menurunkan kadar air dari 2,64\% menjadi $1,66 \%$ 
e. Meningkatkan nilai kalor batubara dari $5190 \mathrm{kkal} / \mathrm{kgram}$ menjadi 7097,24 $\mathrm{kkal} /$ kgram

4. Batubara kualitas rendah asal Mallawa jenis subbituminus dapat ditingkatkan kualitasnya menjadi batubara Low - Volatile Bituminous Type $C$ sesuai dengan standart ASTM- D338 dan SNI 13-6011-1999

\section{Ucapan Terima Kasih}

Ucapan terima kasih diberikan kepada :

1. Kemenristekdikti yang telah memberikan sponsor beaya penelitian sehingga penelitian ini dapat diselesaikan

2. Direktur Politeknik Negeri Ujung Pandang yang telah menjadi penyalur dana penelitian lewat Dipa Politeknik Negeri Ujung Pandang

3. Ketua Jurusan Teknik Kimia yang telah memberikan ijin fasilitas laboratorium

4. Pihak analis dan teknisi serta kedua mahasiswa Wahid dan Noah yang telah ikut mengerjakan penelitian ini hingga selesai, serta banyak pihak yang telah banyak membantu.

\section{Daftar Pustaka}

[1] Adiarso, dkk. 2010, Teknologi Pemanfaatan Batubara Peluang dan Tantangan. Balai Besar Teknologi Energi BPPT PUSPIPTEK, Tangerang

[2] ASTM D 5142-02, 2010, Standards Test Methods for Proximate Analysis of The Analysis Sample of Coal and Coke by Instrumental Procedures.

[3] Bambang V.Luhkiputro. 2004. “ Upaya Pengurangan Kadar Sulfur Batubara Sulawesi Selatan Melalui Serangkaian Proses Desulfurisasi dan Regenerasi Larutan “ Jurnal Intek. (Teragreditasi). No 1. Tahun ke 11

[4] Budiraharjo,I.,2011,Industri batubara Indonesia Terjemah bebas artikel "Indonesia sekitan jijou" oleh Masafumi Uehara, JCOAL Journal Vol 18, Januari 2011. (JCOAL Resources Development Division)

[5] Borthakur,S.danMukherjee,P.C.2001.Chemical Demineralization/Desulphurization of Sulphur Coal Using Sodium Htdroxide and acid Solutions. May. Elsevier Science Ltd.

[6] Erwin J., dkk.2015., Pengaruh suhu dan waktu karbonisasi terhadap nilai kalor dan karakteristik pada pembuatan bioarang berbahan baku pelepah aren ,jurnal : Teknik Kimia USU, Vol. 4, No. 2.

[7] Hartanto, Singgih dan Ratnawati, Pembuatan Karbon aktif dari Tempurung Kelapa Sawit dengan Metode Aktivasi Kimia, Jurnal Sains Materi Indonesia, ISSN : 1411-1098, Vol. 12, No. $1,2010$.

[8] Rustiadi P. \& Susanto,2003, Proses pengolahan batubara Indonesia untuk kokas metalurgi dengan metode coal blending. Pusat penelitian metalurgi LIPI, Tangerang.

[9] Siahaan dkk., 2013, Penentuan Kondisi Optimum Suhu dan Waktu Karbonisasi pada Pembuatan Arang dari Sekam Padi, Jurnal Teknik Kimia USU, 2(1)

[10] Suganal, Kokas dari Batubara Non Coking Indonesia ,Prosiding Seminar Nasional XVI"Kimia dalam Industri dan Lingkungan, Jaringan Kerjasama Kimia Indonesia, Yogyakarta, Desember 2007.

[11] Swastanti B.,dan Herman.B.,2009. Demineralisasi / Desulfurisasi Batubara Malawa Menggunakan Larutan Natrium Hidroksida dan Asam Khlorida , Penelitian Laboratorium, Hibah Bersaing, DP2M.Dikti Indonesia 